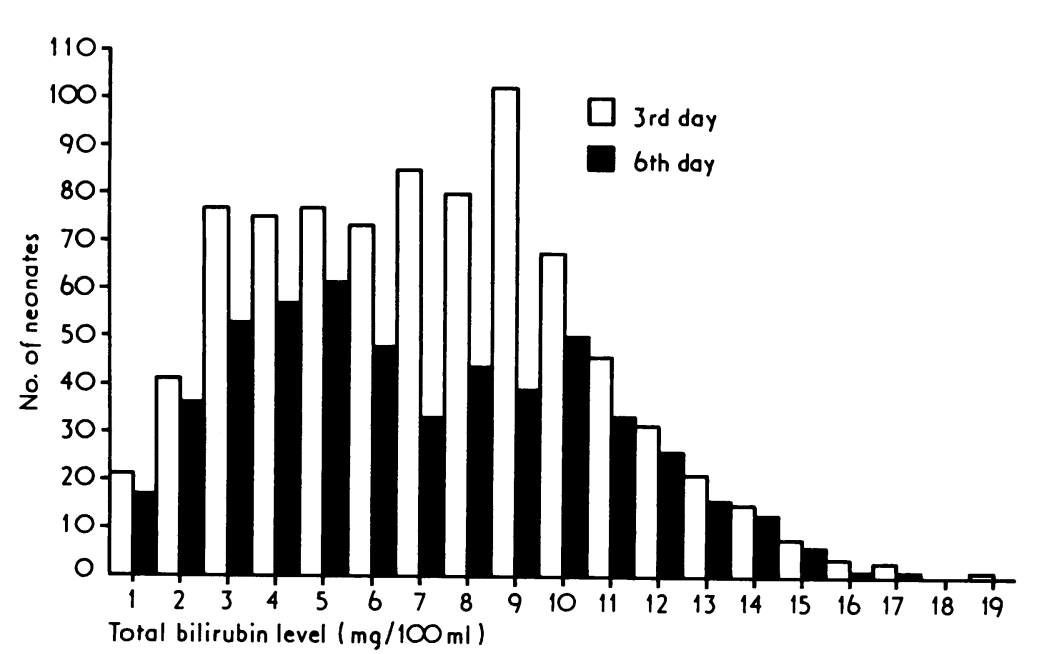

of oxytocin in labour and an increase in the mean bilirubin concentration in the neonates. Our results ${ }^{1}$ obtained from examination of mean bilirubin concentrations in a prospective study of 1,353 labours and neonates agree with the relationship they have shown, but we differ from the conclusion drawn. Possible explanations for this come to mind and deserve comment:

(1) In the study by Dr. Gould and his colleagues serum bilirubin concentrations were estimated on blood taken from the cord at birth and from the baby on the sixth day of life. We suggest that the timing of these blood samples was not ideal for the purpose of this study. It is not to be expected that the bilirubin concentration wou.d be raised in cord blood specimens, whereas by the sixth day of life it can be shown that it has passed its peak and is decreasing. The figure shows the distribution of mean total bilirubin concentrations on the third and sixth days of life in our series of 815 neonates resulting from labours induced or accelerated with oxytocin. It will be seen that on the third day the peak incidence of neonates is associated with a bilirubin concentration of $8 \mathrm{mg} / 100 \mathrm{ml}$ whereas by the sixth day the peak incidence of neonates has a bilirubin concentration of only $5 \mathrm{mg} / 100 \mathrm{ml}$ This suggests that in most neonates the bilirubin concentrations are falling by the sixth day. A similar trend is reported by McConnell et al. ${ }^{2}$ who found that on the fifth day serum bilirubin concentrations were $32 \%$ lower than on the third day in bottle-fed infants.

(2) Several workers ${ }^{1-4}$ other than Gould and his colleagues have tried to show an association between a raised mean neonatal bilirubin concentration and the maternal administration of oxytocin. With the exception of Davies et al. ${ }^{3}$ none have yet found a significant relationship between the use of maternal oxytocin in labour and the mean bilirubin concentration of the neonates. Even Davies et al. claimed only that the as sociation was of minimal significance $(\mathbf{P}<$ 0.05 , method of statistical analysis not stated). However, after labours induced by amniotomy and oxytocin we have shown that the mean total dose of oxytocin received by the mothers whose babies were normal (bilirubin concentration $<12 \mathrm{mg}$ / $100 \mathrm{ml}$ ) was only $9.91 \mathrm{U}$, whereas mother of neonates with hyperbilirubinaemia (bilirubin concentration $>12 \mathrm{mg} / 100 \mathrm{ml}$ ) received a mean total dose of $18.77 \mathrm{U}$ of oxytocin. This difference between the total doses of oxytocin administered is highly significant ( $t$ test: $\mathrm{P}<0.001$ ). Furthermore, we found that the proportion of neonates who developed hyperbilirubinaemia increased in direct relation to the increasing total dose of oxytocin administered. This association was also highly significant (Wilcoxon's test of differences between mean ranks: $P<0.001)$.

Our results support the association between the use of oxytocin in labour and the subsequent development of mild neonatal jaundice, though other factors are involved.-I am, etc.,

BRIAN ALDERMAN JOHN M. BEAZLEY

Department of Obstetrics and Gynaecology,

University of Liverpool Beazley, J. M., and Alderman, B., fournal of
Obstetrics and Gynaecology of the British Commonwealth. In press. 2 McConnell, J. B., Glasgow, J. F. T., and McNair,

Davies, D. P., et al., British Medical fournal, 1973, 3, 476.

G23. A., and Hudson, F. P., Lancet, 1972, 2,

\section{Minocycline and $\beta$-haemolytic Streptococci}

SIR,-Resistance of $\beta$-haemolytic streptococci to the tetracyclines can be a clinical problem. ${ }^{1-3}$ Therefore it is of interest that a new analogue of tetracycline, minocycline (Minocin, Lederle), is now available with reports of its activity against tetracyclineresistant streptococci.45 To compare in vitro this activity with that of tetracycline 63 $\beta$-haemolytic streptococci were obtained from a variety of clinical sources. Dilutions of each antibiotic were made and added to $10 \%$ horse-blood agar (Oxoid, Base No. 2) to yield culture plates with a range of final antibiotic concentrations from 0.3 to 20 $\mu \mathrm{g} / \mathrm{ml}$. The test organisms were grown overnight at $37^{\circ} \mathrm{C}$ in Todd-Hewitt broth (Oxoid) and were diluted $1 / 50$ before each was "spotted" on to an antibiotic-free control plate and on to each antibiotic-concentration plate. After overnight incubation at $37^{\circ} \mathrm{C}$ the inoculated plates were examined for the presence or absence of growth.

With ordinary dosage of tetracycline $(250$ $\mathrm{mg}$ six-hourly) maximal blood levels of $2-4 \mu \mathrm{g} / \mathrm{ml}$ may be expected, ${ }^{6}$ whereas for minocycline at recommended dosage (200 $\mathrm{mg}$ "loading" and $100 \mathrm{mg}$ 12-hourly thereafter) the mean serum concentration over a six days' course is between 1.53 and 2.30 $\mu \mathrm{g} / \mathrm{ml}^{7}$ Therefore to assess potential resistance among the test organisms "threshold" minimum inhibitory concentration values were adopted of $2.5 \mu \mathrm{g} / \mathrm{ml}$ tetracycline and $1.25 \mu \mathrm{g} / \mathrm{ml}$ minocycline, with the results shown in the table.

\begin{tabular}{|c|c|c|}
\hline \multirow{2}{*}{$\begin{array}{c}\text { No. of } \\
\text { Strains Tested }\end{array}$} & \multicolumn{2}{|c|}{ No. $(\%)$ of Strains inhibited by } \\
\hline & $\begin{array}{l}\text { Tetracycline } \\
\leqslant 2.5 \mu \mathrm{g} / \mathrm{ml}\end{array}$ & $\begin{array}{l}\text { Minocycline } \\
\leqslant 1 \cdot 25 \mu \mathrm{g} / \mathrm{ml}\end{array}$ \\
\hline $\begin{array}{rr}\text { Group A } & 33 \\
\text { B } & 15 \\
\text { C } & 9 \\
\text { G } & 6\end{array}$ & $\begin{aligned} 16 & (48) \\
2 & (13) \\
5 & (55) \\
3 & (50)\end{aligned}$ & $\begin{aligned} 22 & (66) \\
2 & (13) \\
5 & (55) \\
3 & (50)\end{aligned}$ \\
\hline
\end{tabular}

In vitro minocycline seems to have some advantages over tetracycline against group A $P$-haemolytic streptococci but not against strains of groups B. C, or G. However, it is debatable whether or not this represents any real advantage in vivo.-I am, etc.,

Rosemary E. T. MCGILI

Microbiology Department,
Ayrshire Central Hospital,

Irvine

1 Garrod, L. P., Lambert, H. P., and O'Grady, F. Antibiotic and Chemotherapy, 4th edn., p. $15 i$. Edinburgh, Churchill Livingstone, 1973 . p. 191.
Robertson, M. H., British Medical fournal, 1973, 4,84 . 3 Fallon, R. J., British Medical fournal, 1973, 4,

Steigbigel, N. N., Reed, C. W., and Finland, M.,
American fournal of American 179.

5 Garrod, L. P., Lambert, H. P., O'Grady, F. Antibiotic and Chemotherapy, 4th edn., p. 161 . Edinburgh, Churchill Livingstone, 1973.

Antibiotic and Chembert, H. P., O'Grady, F. Antibiotic and Chemotherapy, 4th edn., p. 154 7 Frisk, A. R., Turevall, G., Antimicrobial Agents
and Chemotherapy, 1969, 8, 335.

\section{Sun, Wind, Sand and the Skin of Children}

SIR,-Your leading article (13 July, p. 72) and the letter from Dr. E. J. Moynahan (10 August, p. 410) prompt report of the observation that infants suffering from atopic lesions of the skin or napkin dermatitis need not suffer exacerbation of their symptoms when involuntarily exposed to the desiccating action of sun, wind, and sand when on holiday.

The mothers of 11 patients (age range 10 months to 6 years) with symptoms currently in remission expressed anxiety, from previous experience, that exacerbation would occur during forthcoming seaside holidays. This group and five other children (age range 4 months to 2 years) were questioned about the provision of adequate sun protection (clothing, hat, "sun cream") and relevant advice was given-this generally reinforcing previous sensible practice. In addition, application of Parfenac cream (bufexamac 5\%) applicaand evening was prescribed, all 16 childr morning previously achieved the current remission of their pymptoms with this preparation (maximum time in remission seven months, minimum one month)

When seen subsequently 12 children $(75 \%)$ had remained symptom-free, $3(18.75 \%)$ had had a flare-up equivalent to the original presenting condition, and $1(6.25 \%)$ reported eczematous area in a new site (the knees) which lasted for the duration of the holiday only. The three with a severe flare-up returned about $75 \%$ of their prescribed ointment and all were from the group who had not previously experienced a flareup of symptoms under holiday conditions. up of symptoms under holiday conditions. All the remainder returned quantities suggesting
the preparation had been used as prescribed.

In addition to the advantage of being a non-steroid, this anti-inflammatory agent has a bland, moisturing base that is not painful on application and consequently is generally well tolerated by children. While sensible clothing and gradual exposure remain the best method of avoiding the adverse effects 